\title{
Hipertensão arterial sistêmica primária
}

\section{Essential Arterial Hypertension}

\author{
Fernando Nobre ${ }^{1}$, Eduardo Barbosa Coelho², Paulo César Lopes ${ }^{3}$, Tufik J. M. Geleilete ${ }^{4}$
}

\begin{abstract}
RESUMO
Hipertensão Arterial Sistêmica (HAS) é doença de alta prevalência e determinante de alta morbidade e mortalidade senão adequadamente diagnosticada e apropriadamente tratada.

O diagnóstico depende da medida correta da pressão arterial (PA) utilizando-se atualmente métodos alternativos à medida convencional de consultório como a Monitorização Ambulatorial da Pressão Arterial (MAPA) ou a Monitorização Residencial da Pressão Arterial (MRPA).

Uma adequada estratificação do risco adicional ao valor da PA obtido é indispensável para uma planificação do tratamento e o alcance das metas desejadas para cada grupo de indivíduos.

Manter os pacientes sob tratamento é necessário e desejável para que os benefícios auferidos com o tratamento, medicamentoso e não medicamentoso, sejam obtidos.
\end{abstract}

Palavras-chave: Hipertensão Arterial Sistêmica. Diagnóstico da Hipertensão Arterial. Tratamento da Hipertensão Arterial.

\section{Conceltos}

Hipertensão Arterial Sistêmica (HAS) é, ao mesmo tempo, fator de risco para o desenvolvimento de doenças cardiovasculares (DCV) e síndrome com manifestações próprias e características peculiares.

As Diretrizes Brasileiras de Hipertensão VI (DBH VI) ${ }^{1}$ conceituam HAS como "uma condição clínica multifatorial caracterizada por níveis elevados e sustentados de pressão arterial (PA). Associa-se frequentemente a alterações funcionais e/ou estruturais dos órgãos-alvo (coração, encéfalo, rins e vasos sanguíneos) e a alterações metabólicas, com consequente aumento do risco de eventos cardiovasculares fatais e não-fatais".

Ainda de acordo com essas mesmas diretrizes são considerados portadores de HAS indivíduos com PA igual ou superior a 140 x $90 \mathrm{~mm} \mathrm{Hg}$ (Tabela 1) enquanto que para o "Guideline" Europeu de Hipertensão de 2013,2 a classificação dos indivíduos com hipertensão é a que está na Tabela 2.

Nas DBH VI e Guideline Europeu os grupos identificados, respectivamente, como "Limítrofe" e "Normal Alto", assim foram definidos com a finalida-
1. Coordenador da Unidade de Hipertensão do Hospital das Clínicas FMRP-USP. Professor de pós-graduação da FMRP-USP

2. Professor Associado do Departamento de Clínica Médica da FMRP-USP.

3. Médico Assistente do Departamento de Clínica Médica da Disciplina de Nefrologia da FMRP-USP.

4. Professor do Departamento de Clínica Médica da Universidade de Ribeirão Preto - UNAERP
Correspondência: Avenida Independência, 3767 CEP: 14026-150 Ribeirão Preto/SP fernando.nobre@uol.com.br

Artigo recebido em 26/08/2013 Aprovado para publicação em 20/09/2013 


\section{Tabela 1}

Classificação do comportamento da Pressão Arterial, pela medida de consultório (> 18 anos) segundo as Diretrizes Brasileiras de Hipertensão VI. ${ }^{1}$

\begin{tabular}{lcc}
\hline Classificação & Pressão sistólica $(\mathrm{mmHg})$ & Pressão diastólica $(\mathrm{mmHg})$ \\
\hline Ótima & $<120$ & $<80$ \\
Normal & $<130$ & $<85$ \\
Limítrofe* & $130-139$ & $85-89$ \\
Hipertensão estágio 1 & $140-159$ & $90-99$ \\
Hipertensão estágio 2 & $160-179$ & $100-109$ \\
Hipertensão estágio 3 & $\geq 180$ & $\geq 110$ \\
Hipertensão sistólica isolada & $\geq 140$ & $<90$ \\
\hline
\end{tabular}

* Quando as pressões sistólica e diastólica situam-se em categorias diferentes, a maior deve ser utilizada para classificação da pressão arterial.

\section{Tabela 2}

Definição e classificação do comportamento da Pressão Arterial (em mmHg) nas medidas de consultório, segundo o "Guideline" das Sociedades Europeias de Cardiologia e Hipertensão Arterial 2013. ${ }^{2}$

\begin{tabular}{lccc}
\hline Categoria & Sistólica & & Diastólica \\
\hline Ótima & $<120$ & e & $<80$ \\
Normal & $120-129$ & e/ou & $80-84$ \\
Normal Alta & $130-139$ & e/ou & $85-89$ \\
Grau 1 & $140-159$ & e/ou & $90-99$ \\
Grau 2 & $160-179$ & e/ou & $100-109$ \\
Grau 3 & $\geq 180$ & e/ou & $\geq 110$ \\
Sistólica Isolada & $\geq 140$ & e & $<90$ \\
\hline
\end{tabular}

de de aumentar a importância da necessidade de diagnosticar precocemente alterações do comportamento da PA na população em geral.

A hipertensão está nitidamente associada a várias complicações, como acidente vascular encefálico (AVE), doença arterial periférica (DAP), insuficiência cardíaca (IC), doença renal crônica (DRC), infarto agudo do miocárdio (IAM) e doença arterial coronariana (DAC) (Figura 1).

O tratamento com adequado controle da pressão arterial tem se mostrado eficaz em reduzir a ocorrência de complicações decorrentes da HAS bem como redução da mortalidade (Figura 2).

\section{Epidemiologia}

A prevalência da hipertensão arterial no Brasil, avaliada por estudos populacionais que possam refletir a situação da doença no país como um todo é ainda desconhecido. Estudos de prevalência, regionais e isolados, levam-nos a crer que em torno de $30 \%$ da população adulta apresenta hipertensão arterial sistêmica. ${ }^{1}$

Considerando-se valores de PA $\geq 140 / 90 \mathrm{~mm}$ $\mathrm{Hg}, 22$ estudos encontraram prevalências entre 22,3\% e $43,9 \%$, (media de $32,5 \%$ ), com mais de $50 \%$ entre 60 e 69 anos e $75 \%$ acima de 70 anos..$^{5,6}$

Entre os gêneros, a prevalência foi de 35,8\% 


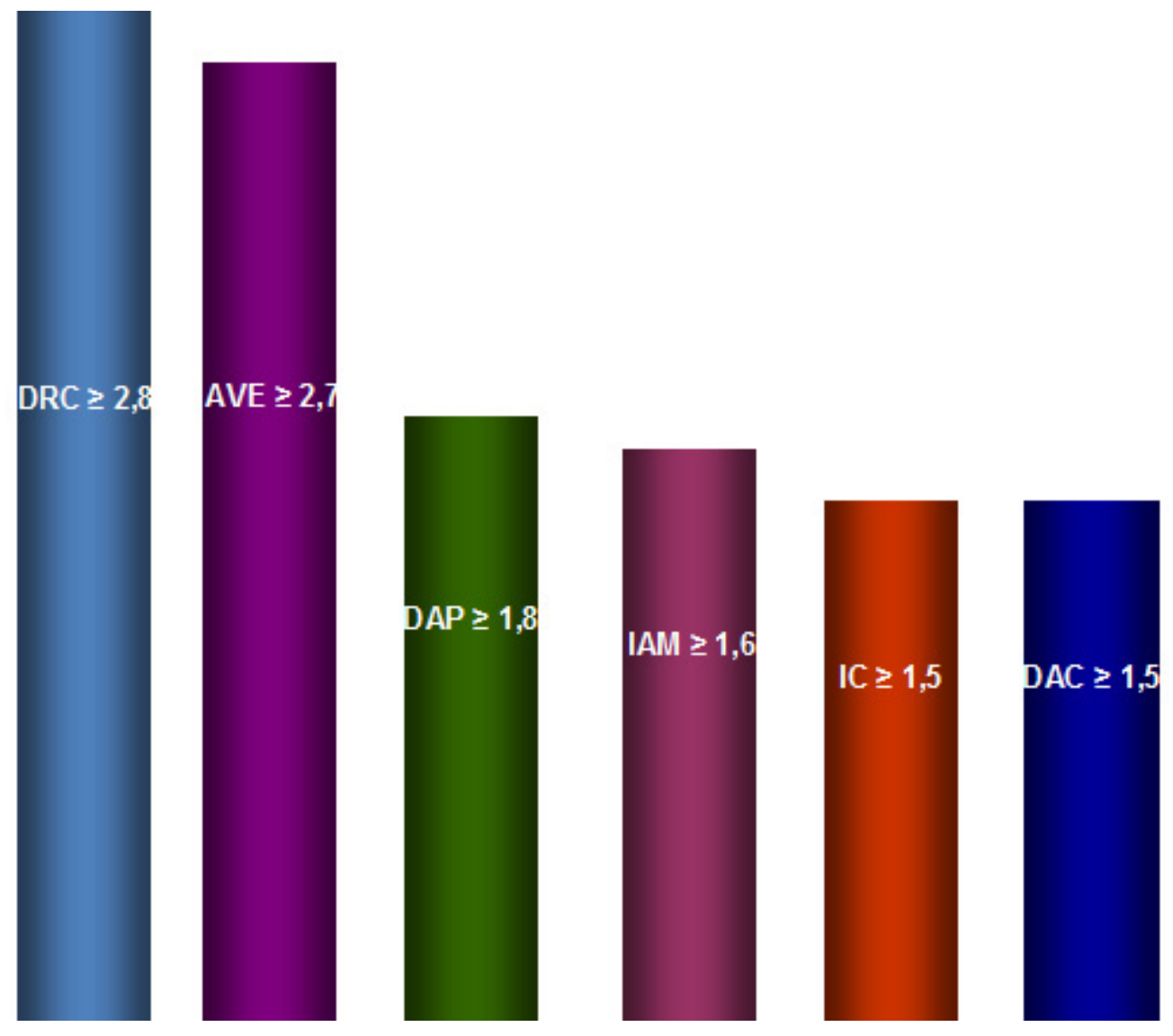

Figura 1. Risco relativo imposto pela Hipertensão Arterial Sistêmica. ${ }^{3}$

$\mathrm{DRC}$ = Doença Renal Crônica; AVE = Acidente Vascular Encefálico; DAP = Doença Arterial Periférica; IAM = Infarto Agudo do Miocárdio; IC = Insuficiência Cardíaca e DAC = Doença Arterial Coronariana.

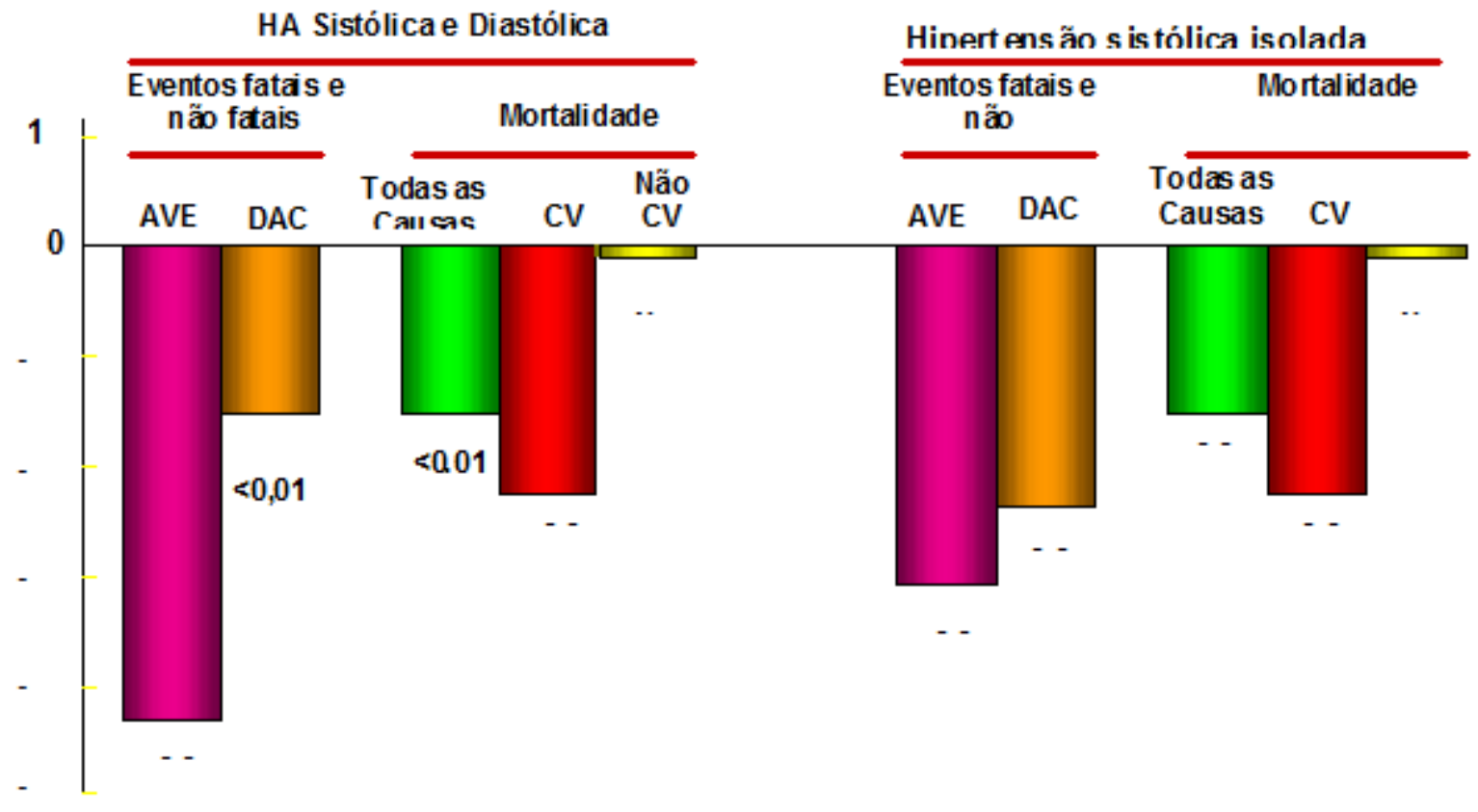

Figura 2. Benefícios obtidos com o tratamento da hipertensão arterial sistêmica. ${ }^{4}$

$\mathrm{HÁ}=$ Hipertensão Arterial; AVE = Acidente Vascular Encefálico; DAC = Doença Arterial coronariana; CV = Cardiovascular. 
nos homens e de $30 \%$ em mulheres, semelhante à de outros países. Revisão sistemática quantitativa de 2003 a 2008, de 44 estudos em 35 países, revelou uma prevalência global de $37,8 \%$ em homens e $32,1 \%$ em mulheres. ${ }^{7}$

\section{Etiopatogenia e fisiopatologia}

A hipertensão arterial é uma síndrome poligênica e compreende aspectos genéticos, ambientais, vasculares, hormonais, renais e neurais.

Fatores Genéticos: a hereditariedade desempenha papel fundamental na gênese da hipertensão. A hipertensão arterial é, pois, quantitativa, complexa e poligênica sendo o resultante final da influência dos fatores ambientais sobre a expressão de certos genes. Assim como em várias doenças, objetiva-se identificar os genes participantes da gênese da hipertensão arterial.

Fatores Ambientais: Inquestionavelmente, o ambiente influi de forma considerável, visto que mudanças de hábitos alteram o comportamento da pressão arterial. São clássicos os estudos de indivíduos pertencentes a grupos populacionais que não apresentam hipertensão arterial e que, ao mudarem para locais de alta prevalência de hipertensão, tornam-se hipertensos. ${ }^{8}$

O sal tem importância na gênese da HAS em indivíduos geneticamente predispostos. O excesso de sal na alimentação e a incapacidade dos rins de excretar a sobrecarga de sódio induzem hipertensão por aumento do volume plasmático, da pré-carga e, consequentemente, do débito cardíaco. Outros mecanismos relacionados ao sal na gênese e na sustentação da hipertensão arterial estão sintetizados no Quadro 1. ${ }^{9}$

A sensibilidade ao sal é variável e pode ser avaliada pela variação da pressão arterial quando se faz uma carga salina. Os indivíduos chamados de resistentes ao sal, a despeito do excesso de sal ingerido, não apresentam maior elevação da PA, ao contrário daqueles sensíveis. Os negros e os idosos são, em geral, os mais sensíveis ao sal entre os hipertensos.

Fatores Vasculares: Segundo os conceitos clássicos da hemodinâmica, a pressão arterial é determinada pelo débito cardíaco multiplicado pela resistência vascular periférica total. Esses determinantes dependem da interação de uma série de fatores. A hipertensão arterial pode surgir por anormalidades em um deles ou em ambos.
A constrição funcional da musculatura lisa é considerada um dos principais mecanismos envolvidos na hipertensão arterial. A elevada resistência vascular periférica determinada pela hipertrofia da parede vascular terá como consequência o aumento na contratilidade da musculatura lisa dos vasos.

A disfunção endotelial tem também participação na gênese da hipertensão arterial. Sabemos que o endotélio atua na regulação do tônus vascular e da resistência vascular periférica, sintetizando substâncias vasoativas, tais como o vasodilatador óxido nítrico e o peptídeo vasoconstritor endotelina.

Rins: Está bem estabelecido que uma elevação da pressão de perfusão arterial renal resulta em aumento da excreção de sódio e água. Quando a PA se eleva, a ativação do fenômeno pressão-natriurese promove excreção de sódio e água até que ela seja reduzida a valores normais. Portanto, os rins servem como feed back negativo para a regulação, em longo prazo, da pressão arterial pelo ajuste do volume plasmático. A hipertensão arterial pode, então, se desenvolver quando se altera a capacidade renal de excretar sódio e água. Essa hipótese é corroborada pela ação dos antihipertensivos que promovem excreção de sódio e água, resultando em controle da PA.

Sistema Renina-Angiotensina-Aldosterona: A renina é uma enzima que, sob a ação de alterações na pressão da arteríola aferente renal e concentração de sódio na mácula densa, é liberada do aparelho justaglomerular e, ao interagir com seu substrato

\section{Quadro 1}

Papel do Sal na Gênese e Sustentação da Hipertensão Arterial 9

- Aumento de volume plasmático

- Inibição da Na-K-ATPase

- Aumento da reatividade ou sensibilidade a substâncias vasoconstritoras

- Disfunção autonômica

- Aumento do turnouver das catecolaminas

- Aumento da sensibilidade dos -1- receptores

- Diminuição da afinidade dos -2-receptores

- Predisposição genética

- Sensibilidade ao sal

- Resistência ao sal 
plasmático angiotensinogênio, transforma-se em angiotensina I. A angiotensina I, uma substância inativa do ponto de vista vascular, por sua vez, principalmente sob a ação de uma enzima conversora, nos pulmões, transforma-se em angiotensina II, essa com forte ação sobre os vasos. A angiotensina II promove vasoconstrição, aumenta o tônus simpático, estimula a secreção de aldosterona, estimula a reabsorção de sódio e concorre para a liberação de hormônio antidiurético.

Sistema nervoso simpático: Há fortes evidências de que o sistema nervoso simpático desempenhe um papel importante por meio de sua atividade aumentada na gênese e na sustentação da HAS. ${ }^{10}$ Em geral isso é mais frequentemente observado em indivíduos jovens hipertensos, que se caracterizam por apresentar débito cardíaco e frequência cardíaca aumentados, enquanto a resistência periférica é normal ou mesmo reduzida.

Obesidade: A obesidade central está frequentemente associada à dislipidemia e intolerância à glicose. Estudos epidemiológicos demonstram claramente a relação entre a obesidade e hipertensão arterial. ${ }^{11}$ Ainda não estão definidos os mecanismos exatos. Acredita-se que esteja relacionada à hiperinsulinemia secundária à resistência insulínica, além de estimulação simpática.

Também há correlação com a retenção de fluidos.

Insulina: A associação de hiperinsulinemia e hipertensão arterial foi analisada em vários estudos clínicos. A resistência insulínica e a hiperinsulinemia estão presentes em metade dos pacientes não obesos hipertensos e em pacientes obesos e portadores de diabetes tipo II.

Indivíduos com obesidade andróide apresentam altos níveis de insulina plasmática frequentemente intolerância à glicose, hipertrigliceridemia e hipertensão arterial, constituindo importante quadro metabólico (Figura 3).

Todas as pessoas obesas apresentam algum grau de resistência à insulina, possivelmente secundária à redução da função dos receptores insulínicos.

A insulina é um hormônio trófico, com seus receptores amplamente distribuídos no endotélio e células musculares lisas dos vasos. Além de sua ação trófica, pode também elevar a pressão arterial pelo aumento da atividade do sistema nervoso simpático e da reabsorção renal de sódio e, consequentemente, aumentando a volemia e o débito cardíaco.

FATORES GENÉTICOS

FATORES ADQUIRIDOS

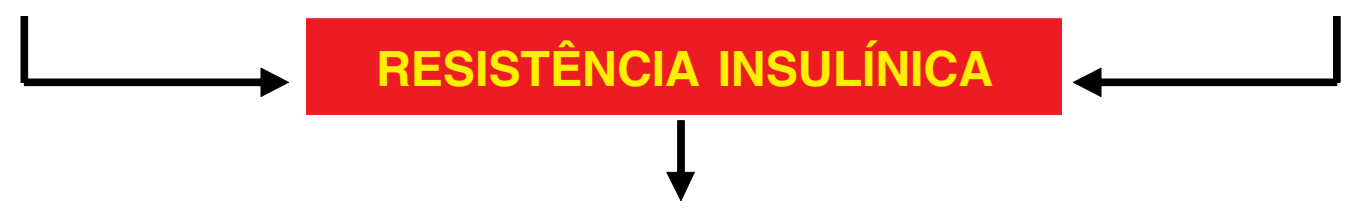

HIPERINSULINEMIA

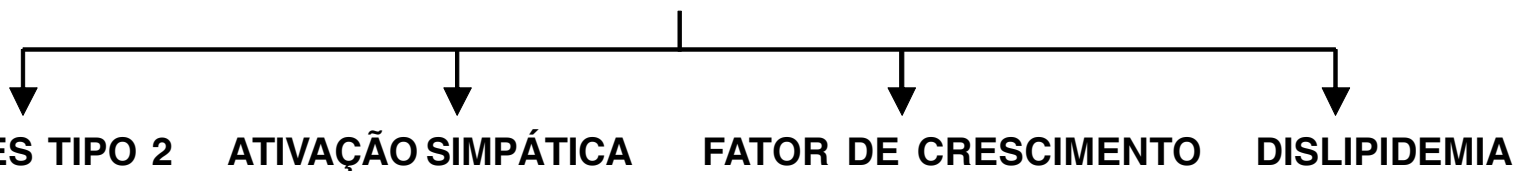

DIABETES TIPO 2 ATIVAÇÃO SIMPÁTICA FATOR DE CRESCIMENTO DISLIPIDEMIA

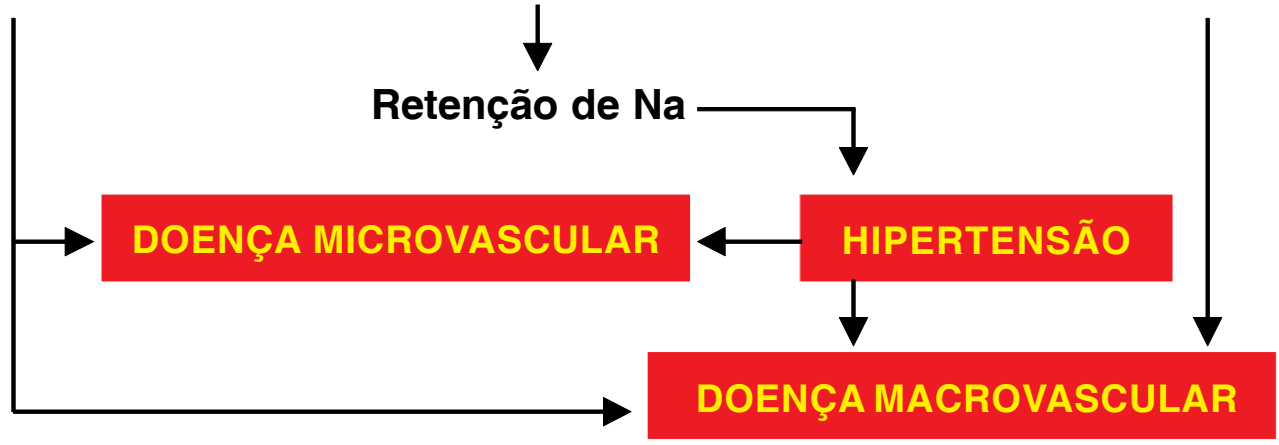

Figura 3. Alterações metabólicas e hipertensão arterial. 


\section{Diagnóstico e estratificação do risco}

A maioria dos pacientes hipertensos é assintomática. O diagnóstico de HAS é feito pela obtenção de medida da PA. As DBH VI 1 apontam (Tabela 3) os procedimentos adequados para a obtenção da medida da pressão arterial.
Para o diagnóstico da HAS a medida apropriada da pressão arterial é fator fundamental.

A escolha do manguito adequado é fundamental, além das demais condutas expressas na tabela 3 , para obtenção da medida correta da pressão arterial. Os manguitos adequados para cada condição estão apontados na Tabela 4.

\section{Tabela 3}

Procedimentos para obtenção da Pressão Arterial segundo as DBH VI. ${ }^{1}$

\section{Preparo do paciente:}

1. Explicar o procedimento ao paciente e deixá-lo em repouso por pelo menos 5 minutos em ambiente calmo. Deve ser instruído a não conversar durante a medida. Possíveis duvidas devem ser esclarecidas antes ou após o procedimento.

2. Certificar-se de que o paciente NÃO:

- Está com a bexiga cheia

- Praticou exercícios físicos há pelo menos 60 minutos

- Ingeriu bebidas alcoólicas, café ou alimentos

- Fumou nos 30 minutos anteriores

3. Posicionamento do paciente

Deve estar na posição sentada, pernas descruzadas, pés apoiados no chão, dorso recostado na cadeira e relaxado.

O braço deve estar na altura do coração (nível do ponto médio do esterno ou $4^{\circ}$ espaço intercostal), livre de roupas, apoiado, com a palma da mão voltada para cima e o cotovelo ligeiramente fletido.

\section{Para a medida propriamente:}

1. Obter a circunferência aproximadamente no meio do braço. Após a medida selecionar o manguito de tamanho adequado ao braço*.

2. Colocar o manguito, sem deixar folgas, 2 a $3 \mathrm{~cm}$ acima da fossa cubital.

3. Centralizar o meio da parte compressiva do manguito sobre a artéria braquial.

4. Estimar o nível da pressão sistólica pela palpação do pulso radial. O seu reaparecimento corresponderá à PA sistólica.

5. Palpar a artéria braquial na fossa cubital e colocar a campânula ou o diafragma do estetoscópio sem compressão excessiva.

6. Inflar rapidamente até ultrapassar 20 a 30 mmHg o nível estimado da pressão sistólica, obtido pela palpação.

7. Proceder à deflação lentamente (velocidade de $2 \mathrm{mmHg}$ por segundo).

8. Determinar a pressão sistólica pela ausculta do primeiro som (fase I de Korotkoff), que é em geral fraco seguido de batidas regulares, e, após, aumentar ligeiramente a velocidade de deflação.

9. determinar a pressão diastólica no desaparecimento dos sons (fase V de Korotkoff).

10. Auscultar cerca de 20 a $30 \mathrm{mmHg}$ abaixo do ultimo som para confirmar seu desaparecimento e depois proceder à deflação rápida e completa.

11. Se os batimentos persistirem ate o nível zero, determinar a pressão diastólica no abafamento dos sons (fase IV de Korotkoff) e anotar valores da sistólica/diastólica/zero.

12. Sugere-se esperar em torno de um minuto para nova medida, embora esse aspecto seja controverso. ${ }^{10,11}$

13. Informar os valores de pressões arteriais obtidos para o paciente.

14. Anotar os valores exatos sem "arredondamentos" e o braço em que a pressão arterial foi medida.

* Veja Tabela 4, página 262. 


\section{Tabela 4}

Diferentes tipos de manguito aplicáveis à medida da pressão arterial. ${ }^{1}$

\begin{tabular}{lccc}
\hline \multirow{2}{*}{ Denominação do manguito } & Circunferência do braço $(\mathbf{c m})$ & \multicolumn{2}{c}{ Bolsa de borracha $(\mathbf{c m})$} \\
\cline { 3 - 4 } Recém-nascido & $\leq 10$ & 4 & Cargura \\
Criança & $11-15$ & 6 & 8 \\
Infantil & $16-22$ & 9 & 12 \\
Adulto pequeno & $20-26$ & 10 & 17 \\
Adulto & $27-34$ & 12 & 23 \\
Adulto grande & $35-45$ & 16 & 32 \\
\hline
\end{tabular}

Mais recentemente, com o advento de métodos de obtenção da PA fora do consultório, como a Monitorização Ambulatorial da Pressão Arterial MAPA e da Monitorização Residencial da Pressão Arterial - MRPA, pode-se definir quatro comportamentos distintos da PA, a saber: Normotensão Verdadeira; Hipertensão Arterial Verdadeira; Hipertensão do Avental Branco e Hipertensão Mascarada ou Normotensão do Avental Branco.

Na Normotensão Verdadeira há valores normais tanto nas medidas obtidas no consultório como naquelas obtidas pela MRPA ou MAPA. Na Hipertensão Verdadeira ocorre comportamento exatamente oposto obtendo-se valores acima da normalidade em ambas as situações.

Hipertensão do Avental Branco é definida como sendo a situação caracterizada por PA sempre alterada nas medidas convencionais ou de consultório com PA normal durante o período de vigília pela MAPA ou na MRPA, enquanto que a Hipertensão Mascarada ou Normotensão do Avental Branco é caracterizada por valores persistentemente normais nas medidas convencionais, porém alterados na MAPA ou MRPA. ${ }^{12}$

Cada uma dessas condições tem características próprias e aspectos prognósticos peculiares.

A definição desses novos tipos de comportamento da PA com a utilização desses novos métodos de avaliação da pressão arterial deve ser considerada.

A distribuição desses tipos de comportamento na população está expressa na Figura 4 enquanto que um fluxograma para diagnóstico, utilizando essas novas formas de avaliação da PA, está apontado na Figura 5.

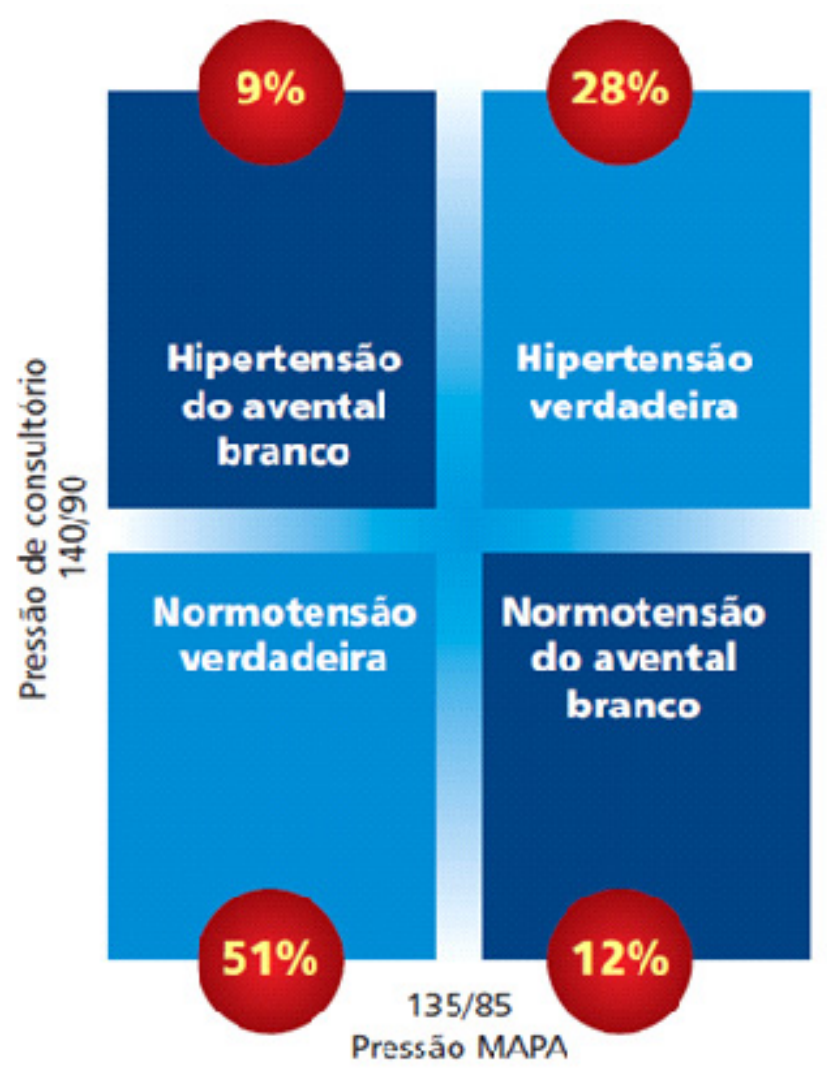

Figura 4. Possibilidades de diagnóstico, de acordo com as medidas de pressão arterial casual e MAPA na vigília ou MRPA. ${ }^{13}$

O diagnóstico da HAS é fundamental, mas deverá ser sempre acompanhado de uma estratificação do risco inerente a cada paciente e que transcende o valor absoluto obtido com a medida da PA. 


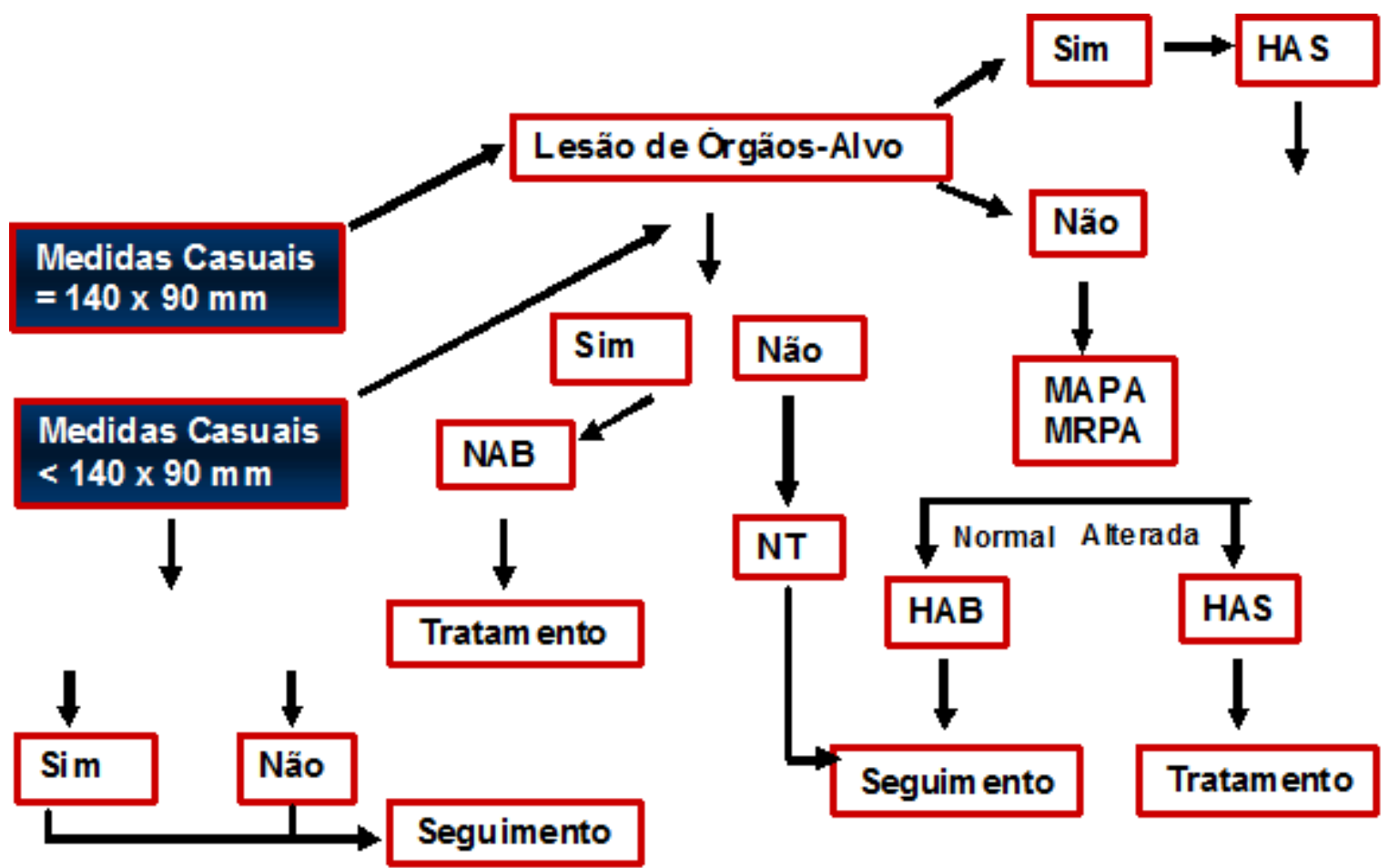

Figura 5. Fluxograma para a avaliação do comportamento da Pressão Arterial sugerido pelo autor.

Inicialmente devemos considerar que há necessidade do conhecimento de outros fatores associados à pressão arterial o que exigirá exames complementares e história clínica dirigida.

A avaliação clínica e laboratorial tem, portanto, objetivos bem definidos e que estão expressos na Tabela 5 .

Para que a estratificação do risco adicional possa ser concluída exames básicos serão necessários em complementação à história clínica. A Tabela 6 exibe os exames complementares fundamentais para serem solicitados ao paciente com alteração da PA.

\section{Tabela 5}

Objetivos da avaliação complementar do paciente com Hipertensão Arterial.

- Confirmar o diagnóstico de HAS por medida da PA

- Identificar fatores de risco para doenças cardiovasculares

- Pesquisar lesões em órgãos-alvo, clínicas ou subclínicas

- Pesquisar presença de outras doenças associadas

- Estratificar o risco cardiovascular global

- Avaliar indícios do diagnóstico de hipertensão arterial secundária
De posse de uma história clínica adequada e desses exames é fundamental que se apliquem esses dados ao modelo de estratificação de risco (Figura 6) para se estabelecer o programa de tratamento e as metas a serem atingidas com o tratamento instituído, já que para cada nível de risco obtido tratamento e metas poderão variar.

\section{Tabela 6}

Avaliação inicial de rotina para os pacientes com Hipertensão Arterial.

- Análise de urina (Classe I, Nível C)

- Potássio plasmático (Classe I, Nível C)

- Creatinina plasmática (Classe I, Nível B) e estimativa do ritmo de filtração glomerular (Classe I, Nível B)

- Glicemia de jejum (Classe I, Nível C)

- Colesterol total, HDL, triglicérides plasmáticos (Classe I, Nível C)*

- Ácido úrico plasmático (Classe I, Nível C)

- Eletrocardiograma convencional (Classe I, Nível B)

* Para obtenção do LDL colesterol utilizar a fórmula: LDLc $=$ Triglicérides $/ 5+$ HDLc - Coleterol Total 


\begin{tabular}{|c|c|c|c|c|c|c|}
\hline \multirow[b]{2}{*}{$\begin{array}{l}\text { Outros fatores de risco ou } \\
\text { doenças }\end{array}$} & \multicolumn{3}{|c|}{ Normotensáo } & \multicolumn{3}{|c|}{ Hipertensáo } \\
\hline & $\begin{array}{c}\text { Ótimo } \\
\text { PAS }<120 \\
\text { OU PAD }<80\end{array}$ & $\begin{array}{c}\text { Normal } \\
\text { PAS } 120-129 \\
\text { Ou PAD } 80-84\end{array}$ & $\begin{array}{c}\text { Limitrofe } \\
\text { PAS 130-139 } \\
\text { cu PAD 85-89 }\end{array}$ & $\begin{array}{c}\text { Estágio } 1 \\
\text { PAS 140-159 } \\
\text { PAD 90-99 }\end{array}$ & $\begin{array}{c}\text { Estágio } 2 \\
\text { PAS 160-179 } \\
\text { PAD 100-109 }\end{array}$ & $\begin{array}{l}\text { Estágio } 3 \\
\text { PAS }>180 \\
P A D>110\end{array}$ \\
\hline Nenhum fator de risco & Risco basal & Risco basal & Risco basal & $\begin{array}{l}\text { Baixo risco } \\
\text { adicional }\end{array}$ & $\begin{array}{l}\text { Moderado } \\
\text { risco } \\
\text { adicional }\end{array}$ & $\begin{array}{l}\text { Alto risco } \\
\text { adicional }\end{array}$ \\
\hline 1-2 fatores de risco & $\begin{array}{l}\text { Baixo risco } \\
\text { adicional }\end{array}$ & $\begin{array}{l}\text { Baixo risco } \\
\text { adicional }\end{array}$ & $\begin{array}{l}\text { Beixo risco } \\
\text { adicional }\end{array}$ & $\begin{array}{l}\text { Moderado } \\
\text { risco } \\
\text { adicional }\end{array}$ & $\begin{array}{l}\text { Moderado } \\
\text { risco } \\
\text { adicional }\end{array}$ & $\begin{array}{c}\text { Risco } \\
\text { adicional } \\
\text { muito al to }\end{array}$ \\
\hline $\begin{array}{l}\geq 3 \text { fatores de risco, LOA ou } \\
5 \mathrm{M}-\mathrm{DM}\end{array}$ & $\begin{array}{l}\text { Moderado } \\
\text { risco } \\
\text { adicional }\end{array}$ & $\begin{array}{l}\text { Moderado } \\
\text { risco } \\
\text { adicional }\end{array}$ & $\begin{array}{l}\text { Alto risco } \\
\text { adicional }\end{array}$ & $\begin{array}{l}\text { Alto risco } \\
\text { adicional }\end{array}$ & $\begin{array}{l}\text { Alto risco } \\
\text { adicional }\end{array}$ & $\begin{array}{c}\text { Risco } \\
\text { adicional } \\
\text { muito al to }\end{array}$ \\
\hline Condiçōes clínicas associadas & $\begin{array}{c}\text { Risco } \\
\text { adicional } \\
\text { muito alto }\end{array}$ & $\begin{array}{c}\text { Risco } \\
\text { adicional } \\
\text { muito alto }\end{array}$ & $\begin{array}{c}\text { Risco } \\
\text { adicional } \\
\text { muito a lto }\end{array}$ & $\begin{array}{c}\text { Risco } \\
\text { adicional } \\
\text { muito alto }\end{array}$ & $\begin{array}{c}\text { Risco } \\
\text { adicional } \\
\text { muito alto }\end{array}$ & $\begin{array}{c}\text { Risco } \\
\text { adicional } \\
\text { muito al to }\end{array}$ \\
\hline
\end{tabular}

(LCA: lesso de órgóos-alvos; SM; sindrome metabólica; DM: dabetes melito).

Figura 6. Estratificação de risco adicional para os pacientes com Hipertensão Arterial de acordo com fatores de risco, condições clínicas associadas e presença de Lesões em Órgãos-alvo. 1

\section{Decisão Terapêutica}

\section{Racional para decisão terapêutica}

Modificações de estilo de vida podem se refletir no retardo do desenvolvimento da HAS em indivíduos com pressão limítrofe.

Tem também impacto favorável nos fatores de risco envolvidos no desenvolvimento ou agravo da hipertensão ${ }^{14-17}$.

Assim, deve ser indicado indiscriminadamente a todos, hipertensos ou não.

O período de tempo recomendado para as medidas de modificação de estilo de vida isoladamente em pacientes hipertensos, e naqueles com comportamento limítrofe da pressão arterial, com baixo risco cardiovascular, é de no máximo seis meses.
Caso não estejam respondendo a essas medidas após três meses, uma nova avaliação, em seis meses, deve ser feita para confirmar o controle da PA. Se esse beneficio ainda não for confirmado, já estará indicada a instituição do tratamento medicamentoso em associação.

Em pacientes com riscos médios, altos ou muito altos, independentemente da PA, a abordagem deve ser combinada (não medicamentosa e medicamentosa) para se atingir a meta preconizada o mais precocemente 1 .

Para a decisão terapêutica, considerar a Tabela 7 e para as metas de PA nas diferentes categorias de risco seguir a Tabela 8 .

Novos estudos não demonstraram haver benefícios com reduções mais intensas da PA como se julgava anteriormente. ${ }^{18,19}$

\section{Tabela 7}

Decisão terapêutica. ${ }^{1}$

\section{Categoria de risco}

Sem risco adicional

Risco adicional baixo

Risco adicional médio, alto e muito alto

\section{Considerar}

Tratamento não-medicamentoso isolado

Tratamento não-medicamentoso isolado por até 6 meses. Se não atingir a meta, associar tratamento medicamentoso

Tratamento não-medicamentoso + medicamentoso 


\section{Tabela 8}

Metas de controle de Pressão Arterial a serem atingidas com o tratamento da Hipertensão Arterial. ${ }^{1}$

\begin{tabular}{lc}
\hline Categoria & Considerar \\
\hline Hipertensos estágios 1 e 2 com risco cardiovascular baixo e médio & $<140 / 90 \mathrm{mmHg}$ \\
Hipertensos e comportamento limítrofe com risco cardiovascular alto e muito alto, & $130 / 80 \mathrm{mmHg}$ \\
ou com 3 ou mais fatores de risco, DM, SM ou LOA & $130 / 80 \mathrm{mmHg}$ \\
\hline
\end{tabular}

(DM: diabetes melito; SM: síndrome metabólica; LOA: lesões em órgãos-alvo).

\section{Tratamento}

O objetivo principal do tratamento anti-hipertensivo é prevenir a morbidade e reduzir a mortalidade cardiovascular associadas à hipertensão arterial sistêmica. A eficácia dos medicamentos anti-hipertensivo hoje disponíveis está bem determinada e é similar. O tratamento não medicamentoso também reduz a pressão arterial, e se associado ao uso de medicamentos pode melhorar as suas eficácias.

Para o tratamento da HAS deve se considerar, portanto: Mudanças de estilo de vida ou Tratamento não medicamentoso e a instituição de Tratamento medicamentoso.

\section{Tratamento não medicamentoso ou mudan- ças de estilo de vida}

Consiste em orientações objetivando reduzir a pressão arterial. A sua aplicação pode reduzir a necessidade de medicamentos anti-hipertensivos e aumentar sua eficácia. Controlar os fatores de risco associados e, concorrer para a prevenção primária da hipertensão e de doenças cardiovasculares associadas é também um objetivo do tratamento não medicamentoso.

Há um elenco de medidas cuja eficácia já está claramente estabelecida como benéficas e que serão apresentadas a seguir.

Redução do Peso ${ }^{20}$. Todos os pacientes com peso acima do ideal $\left(\mathrm{IMC}=\right.$ peso/altura ${ }^{2}$, acima de 25 $\mathrm{kg} / \mathrm{m}^{2}$ ) devem ser encorajados a participar de um programa de atividades físicas aeróbicas e redução da ingestão de calorias, com o objetivo de perder peso. Aproximadamente 50\% dos adultos no Brasil tem sobrepeso ou obesidade, segundo dados do Ministério da Saúde. Em indivíduos obesos, um IMC $<25 \mathrm{~kg} / \mathrm{m}^{2}$ deve ser o objetivo a alcançar. A redução do peso reduz o nível da PAS em torno de 5 a $20 \mathrm{~mm} \mathrm{Hg}$ para cada $10 \mathrm{~kg}$ perdidos. Independente do valor do IMC, a obesidade andróide ou central (circunferência abdominal $102 \mathrm{~cm}$ em homens e $88 \mathrm{~cm}$ em mulheres) é um fator preditivo de doença cardiovascular.

Consumo de Bebidas Alcoólicas. ${ }^{21} \mathrm{O}$ consumo de etanol não deve ultrapassar $30 \mathrm{~g}$ para os homens e $15 \mathrm{~g}$ para as mulheres ao dia, valor que está contido em $60 \mathrm{ml}$ de bebida destilada, $240 \mathrm{ml}$ de vinho ou $720 \mathrm{ml}$ de cerveja. É sabido que o consumo excessivo de bebidas alcoólicas além de aumentar a pressão arterial pode causar resistência à ação antihipertensiva de alguns medicamentos. Seguindo essa recomendação, será possível uma redução aproximada de 2 a $4 \mathrm{~mm} \mathrm{Hg}$ no nível da pressão arterial sistólica.

Atividade Física. ${ }^{22}$ Após avaliação clínica prévia, recomenda-se prática de atividade física aeróbica moderada por pelo menos 30 minutos por dia, na maioria dos dias da semana, se não houver limitação. Dessa forma, pode-se obter uma redução aproximada de 4 a $9 \mathrm{~mm} \mathrm{Hg}$ da PA sistólica. Um programa de atividade física deve iniciar-se com distância não superior a $1.000 \mathrm{~m}$, devendo ser acrescido, semanalmente, 200 a $500 \mathrm{~m}$ até que atinjam aproximadamente $6.000 \mathrm{~m}$. Uma referência é o desenvolvimento de $100 \mathrm{~m}$ por minuto durante as caminhadas.

Restrição de Sal. ${ }^{23}$ Deve ser estimulada em todo paciente hipertenso. Evitar alimentos com elevado teor de sal e prepará-los com pouco sódio não o adicionando aos alimentos já prontos. $\mathrm{O}$ consumo de sal pela população brasileira é em torno de 10 a $12 \mathrm{~g} /$ dia, no entanto, a recomendação ideal é de $6 \mathrm{~g} / \mathrm{dia}$ (100 mEq de sódio). A redução da ingestão de $\mathrm{NaCl}$ apresenta um efeito de redução aproximada de 2 a 8 mm Hg no nível da PA sistólica. Uma regra prática que podemos utilizar é aconselhar um consumo não 
superior a $1 \mathrm{~kg}$ de sal ao mês, se a família tiver, por exemplo, 5 componentes adultos.

Suspensão do Tabagismo ${ }^{24} \mathrm{O}$ tabagismo é importante fator de risco para doenças cardiovasculares e deve ser abolido. Estudos em larga escala tem confirmado que pacientes hipertensos tabagistas, ainda que tratados, apresentam maior incidência de doenças cardiovasculares que os não tabagistas em iguais condições.

Padrão alimentar ideal. O estudo DASH ${ }^{25}$ (Dietary Approachs to Stop Hypertension) preconiza uma dieta com frutas, verduras, derivados desnatados de leite, quantidade reduzida de gorduras saturadas e colesterol com objetivo de promover redução da pressão arterial.

Controle das Dislipidemias. ${ }^{26}$ Uma vez que a associação entre hipercolesterolemia, diabetes e hipertensão está claramente demonstrada, pessoas hipertensas com dislipidemia devem receber orientação nutricional e tratamento medicamentoso, se necessário.

Suplementação de Potássio ${ }^{27}$, Cálcio ${ }^{28}$ e Magnésio $^{29}$. Promovem modesta redução da PA. Entendemos que o uso rotineiro é dispendioso e não deve ser preconizado, sobretudo pela falta de evidências robustas de benefícios.

\section{Tratamento Medicamentoso}

A decisão terapêutica deve basear-se nos va- lores da pressão arterial, na presença ou não de lesão em órgãos-alvo e de fatores de risco associados, que permitem estratificar o risco do paciente a ser tratado (Figura 6).

A redução da pressão arterial com medicamentos reduz a morbidade e mortalidade cardiovascular em pacientes hipertensos.

A decisão terapêutica deveria ser tomada considerando a Tabela 6 e a Figura 7.

De acordo com o VII JNC ${ }^{30}$, os pré-hipertensos não precisam de tratamento medicamentoso, mas são necessárias mudanças do estilo de vida.

O critério de escolha do medicamento deve ser de acordo com as características peculiares de cada paciente, doenças associadas, farmacocinética, farmacodinâmica, idade, fácil posologia dos medicamentos e custos. As características de um agente antihipertensivo ideal estão apontadas na Tabela 9.

ESQUEMAS TERAPÊUTICOS. Os anti-hipertensivos devem reduzir a PA e os eventos cardiovasculares fatais ou não. A utilização de diuréticos ${ }^{31}$, betabloqueadores ${ }^{32}$, inibidores da enzima conversora da angiotensina (IECA) ${ }^{33}$, antagonistas dos receptores AT1 da angiotensina II (AII) ${ }^{34}$ e os antagonistas dos canais de cálcio ${ }^{35} \mathrm{e}$ inibidores diretos da renina ${ }^{36}$ no tratamento da hipertensão demonstraram benefícios cardiovasculares em vários estudos.

\section{Tabela 9}

Características do anti-hipertensivo ideal.

Ser eficaz por via oral

Permitir a administração em menor número possível de tomadas, com preferência para dose única diária

Não ser obtido por meio de manipulação, pela inexistência de informações adequadas de controle de qualidade, bioequivalencia e/ou de interação química dos compostos

Ser utilizado por um período mínimo de quatro semanas, salvo em situações especiais, para aumento de dose, substituição da monoterapia ou mudança das associações em uso
Ser seguro e bem tolerado e com relação de risco/ benefício favorável ao paciente

Ser iniciado com as menores doses efetivas preconizadas para cada situação clinica, podendo ser aumentadas gradativamente ressalvando-se que, quanto maior a dose, maiores serão as probabilidades de efeitos adversos

Ser considerado em associação para os pacientes com hipertensão em estágios 2 e 3 e para pacientes de alto e muito alto risco cardiovascular que, na maioria das vezes, não alcançam a meta de redução da pressão arterial preconizada com a monoterapia

Ter demonstração, em ensaios clínicos, da capacidade de reduzir a morbidade e a mortalidade cardiovasculares associadas à hipertensão arterial (característica para preferência de escolha) 
As classes de anti-hipertensivos disponíveis no Brasil para tratamento da HAS estão apresentados na Tabela 10.

\section{Tabela 10}

Classes de medicamentos anti-hipertensivos disponíveis no Brasil para tratamento da hipertensão arterial.

\section{Diuréticos}

Inibidores adrenérgicos

- Ação central - agonistas alfa-2 centrais

- Betabloqueadores - bloqueadores beta-adrenérgicos

- Alfabloqueadores - bloqueadores alfa-1 adrenérgicos

Vasodilatadores diretos

Bloqueadores dos canais de cálcio

Inibidores da enzima conversora da angiotensina

Bloqueadores do receptor $\mathrm{AT}_{1}$ da angiotensina II

Inibidor direto da renina

Diuréticos. Estão indicados, preferencialmente na hipertensão arterial de negros, obesos e idosos. Sua ação anti-hipertensiva deve-se à redução do volume plasmático seguida da redução da resistência vascular periférica. Deve-se dar preferência aos diuréticos tiazídicos, em baixas doses.

Os diuréticos poupadores de potássio são pouco eficazes como anti-hipertensivos, e seu uso deve ser restrito à associação com os tiazídicos ou os de alça com o objetivo de evitar ou minimizar a hipocalemia.

Os efeitos adversos mais frequentes são hipomagnesemia, hiponatremia, hiperuricemia, hipercalcemia, hipertrigliceridemia, intolerância à glicose e disfunção sexual.

Esses efeitos indesejáveis parecem ser dosedependentes, e, em função do uso de pequenas doses $(12,5 \mathrm{mg}$ a $25 \mathrm{mg} / \mathrm{dia}$ de diuréticos tiazídicos), esperase que possam ser minimizados. Outro aspecto a ser lembrado é que os efeitos colaterais parecem ser mais evidentes no início da terapêutica, não se mantendo com sua continuidade.

O baixo custo do tratamento, além de fortes evidências de reduções de morbidade e mortalidade com o uso são fatores para o emprego dos diuréticos.
Betabloqueadores. Anti-hipertensivos preferenciais para pacientes jovens, hipertensos lábeis e com síndrome hipercinética.

Constituem também primeira opção para os pacientes que apresentam hipertensão associada à doença arterial coronariana, arritmia cardíaca e cefaléia de origem vascular, efeito esse restrito àqueles que ultrapassam a barreira hemato-encefálica (Propranolol, por exemplo).

Agem reduzindo o débito cardíaco e a secreção de renina, readaptando os barorreceptores e diminuindo as catecolaminas nas sinapses nervosas.

Estão contra-indicados na doença pulmonar obstrutiva crônica, nos bloqueios atrioventriculares de $2^{\circ}$ e $3^{\circ}$ graus. Devem ser usados com cautela nos pacientes com vasculopatias periféricas.

Seus efeitos adversos são broncoespasmo, bradicardia, distúrbio da condução atrioventricular; mascaramento dos sintomas de hipoglicemia, especialmente em diabéticos dependentes de insulina; hipertrigliceridemia e redução de HDL-colesterol, além de disfunção sexual. Estes efeitos parecem estar minimizados nos bloqueadores beta adrenérgicos de mais recente geração, incluindo ação vasodilatadora concomitante. ${ }^{37}$

Antagonistas dos Canais de Cálcio. Determinam redução da resistência vascular periférica em consequência da diminuição da concentração de cálcio intracelular na musculatura lisa das artérias.

As reações adversas mais comuns constituemse de taquicardia reflexa, cefaléia, tonturas, rubor facial, edema maleolar, hipertrofia gengival e constipação intestinal.

Antagonistas de canais de cálcio de longa duração de ação devem ser preferidos, em relação aos de curta duração.

Inibidores da Enzima Conversora da Angiotensina. Estão formalmente indicados na hipertensão arterial associada ao diabetes e à insuficiência cardíaca. Estudos demonstraram que reduzem a morbidade e mortalidade cardiovasculares em pacientes com disfunção sistólica do ventrículo esquerdo, sintomáticos ou não, atuando principalmente no processo de remodelação ventricular. São eficazes também em prevenir ou impedir a progressão da insuficiência renal, especialmente nos pacientes diabéticos.

Agem inibindo a enzima conversora da angiotensina, bloqueando a transformação da angiotensina I para II. 
Os efeitos adversos são: tosse seca (reversível após interrupção), angioedema, erupção cutânea, alteração do paladar e hipercalemia, particularmente em indivíduos com doença renal crônica.

São absolutamente contra-indicados em mulheres grávidas ou potencialmente férteis; em pacientes com estenose renal bilateral ou com lesão unilateral e rim único e naqueles pacientes com hipercalemia.

Antagonistas dos Receptores AT1 da Angiotensina II (AII). Agem por meio do bloqueio específico dos receptores AT1 da Angiotensina II. Exercem efeitos cardioprotetores e nefroprotetores em diabéticos tipo II com nefropatia estabelecida.

Devido a sua ação anti-hipertensiva bloqueando as ações da angiotensina II sem aumentar os níveis de bradicinina, explica-se a menor ocorrência de tosse.

Inibidores Adrenérgicos de Ação Central. São menos utilizadas devido a efeitos adversos em geral intoleráveis. Apresentam baixa eficácia para reduzir a PA quando usados como monoterapia.

A alfa-metildopa mantém-se como agente de escolha para tratamento da hipertensão arterial na gravidez, pela sua comprovada segurança nessa condição específica.

Alfa-1 Bloqueadores. São drogas que causam vasodilatação pelo bloqueio seletivo dos receptores alfa -1- adrenérgicos.

Apresentam baixa eficácia como monoterapia. Não são recomendados como drogas de primeira escolha.

Não há contra-indicação para seu uso, porém devem ser utilizados com cautela em idosos devido a possível resposta hipotensora ortostática após a primeira dose. Propiciam discreta melhora do metabolismo lipídico e dos sintomas em pacientes com hipertrofia benigna da próstata. No estudo ALLHAT $31 \mathrm{o}$ grupo tratado com Alfa 1 Bloqueadores foi precocemente interrompido pela ocorrência significativamente maior de insuficiência cardíaca.

Vasodilatadores diretos: Agem na musculatura da parede vascular, promovendo relaxamento com consequente vasodilatação e redução da resistência vascular periférica.

São Inadequados como drogas de primeira escolha, para uso isolado, embora sejam potentes hipotensores.

Seus efeitos adversos são: a retenção hídrica e a taquicardia reflexa.

Se utilizados, devem ser associados a Beta-blo- queadores e diuréticos.

Inibidores diretos da renina: Constituem classe terapêutica de mais recente inclusão na prática clínica. Apresentam vantagens e limitações para seu uso rotineiro.

O representante desta classe é o medicamento Alisquireno, que foi utilizado em associação ao IECA ou BRA em 8561 pacientes diabéticos do tipo 2 com doença cardiovascular e/ou renal em estudo clínico multicêntrico, duplo cego, aleatorizado e placebo controlado (estudo ALTITUDE) ${ }^{38}$, com o objetivo primário de avaliar a incidência de eventos cardíacos fatais ou não, internação hospitalar secundária a insuficiência cardíaca, AVE, morte ou necessidade de Terapia renal substitutiva devido a estágio final de doença renal crônica ou o dobro da concentração da creatinina sérica. O estudo foi interrompido no momento em que havia ocorrido $69 \%$ dos eventos esperados, não demonstrando redução nos desfechos primários. Além disso, um número significativamente aumentado de eventos adversos, como hipercalemia e hipotensão, pesou na decisão da interrupção do estudo pelo comitê de segurança.

Portanto, a despeito do alisquireno ter reduzido a proteinúria em pacientes com nefropatia diabética ${ }^{39}$ e reduzido peptídeos natriuréticos tipo $\mathrm{B}$ em pacientes com insuficiência cardíaca ${ }^{36}$, os resultados do estudo ALTITUDE não autoriza a utilização desta medicação, isoladamente ou em associação aos IECAS e BRAS, para tratamento da nefropatia diabética.

\section{Conduta terapêutica}

O fluxograma preconizado pelas VI Diretrizes Brasileiras de Hipertensão para a instituição da terapêutica anti-hipertensiva e a sua sequência até que as metas preconizadas para o controle da PA sejam atingidas está mostrado na Figura 7.

Com essas intervenções espera-se que a PA seja reduzida até valores que correspondem àqueles que se correlacionem com melhor prognóstico (Tabela 8).

Adesão ao Tratamento. A baixa adesão ao tratamento é alarmante e o nível de controle dos pacientes tratados não é mais animador do que a falta de continuidade com relação às condutas e tratamentos propostos. Os principais fatores que concorrem para a não adesão ao tratamento são os apontados na Tabela $11^{40}$ : 


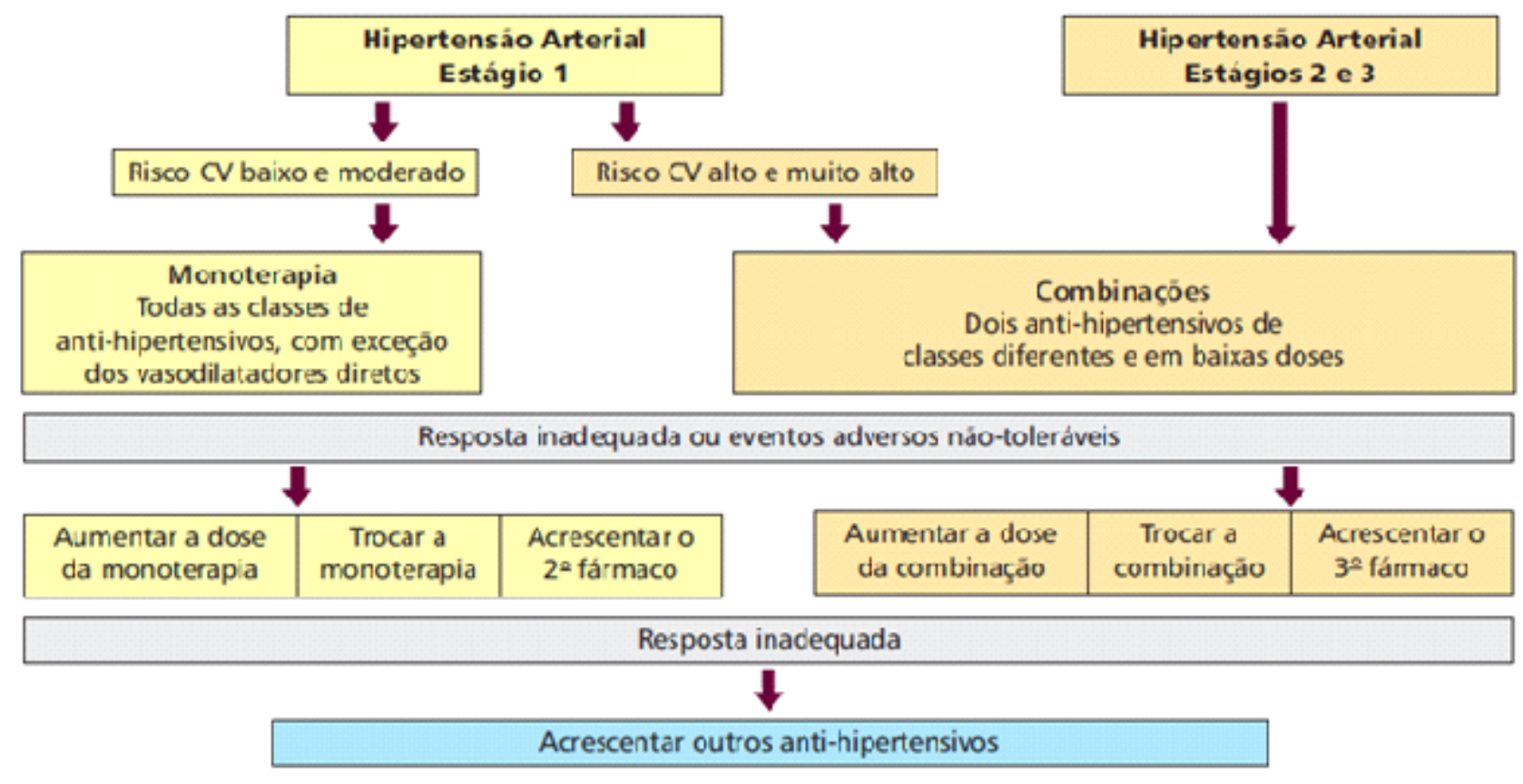

Figura 7. Fluxograma para o tratamento da hipertensão arterial sistêmica.

Tabela 11: Principais fatores que concorrem para a não adesão ao tratamento anti-hipertensivo

\section{Paciente}

- Tem concepções errôneas sobre a doença e o tratamento

- Compreende mal as instruções: não sabe como proceder

- Não possui capacidade ou recursos necessários para seguir o tratamento

- Julga ser incapaz de seguir o tratamento

- Duvida da utilidade do tratamento

- Acredita que os benefícios não valem os esforços

- Demonstra impaciência com a velocidade dos progressos

- Tem outras preocupações para priorizar

\section{Tratamento}

- Esquemas complexos

- Custo

- Efeitos indesejáveis

- Resultados a longo prazo

- Exige demais do paciente

- Qualidade de vida prejudicada

\section{Instituição}

- Política de saúde

- Acesso ao serviço

- Distância

- Tempo de espera

- Duração do atendimento

\section{Profissional}

- É distante, pouco cordial, desinteressado, inacessível, impessoal, formal

- Parece sempre ocupado, com pressa, atende com várias interrupções

- Usa jargão, não considera as dúvidas e preocupações do paciente

- Não informa ou o faz de maneira imprecisa

- Pergunta sobre coisas que o paciente não contaria sequer a amigos

- Não oferece uma atenção contínua e personalizada, com retornos programados 
No Brasil $^{1}$ e no mundo os níveis de conhecimento da HAS, os percentuais de indivíduos que se sabendo com hipertensão arterial estão em uso de medicamentos e desses quantos estão com a PA controlada podem ser observados na Figura $8 .^{1}$

\section{Perspectivas}

O grande desafio em relação à HAS é estabelecer substanciais aumentos no diagnóstico, tratamento, seguimento e controle dentro das metas ideais para cada situação peculiar de pacientes.

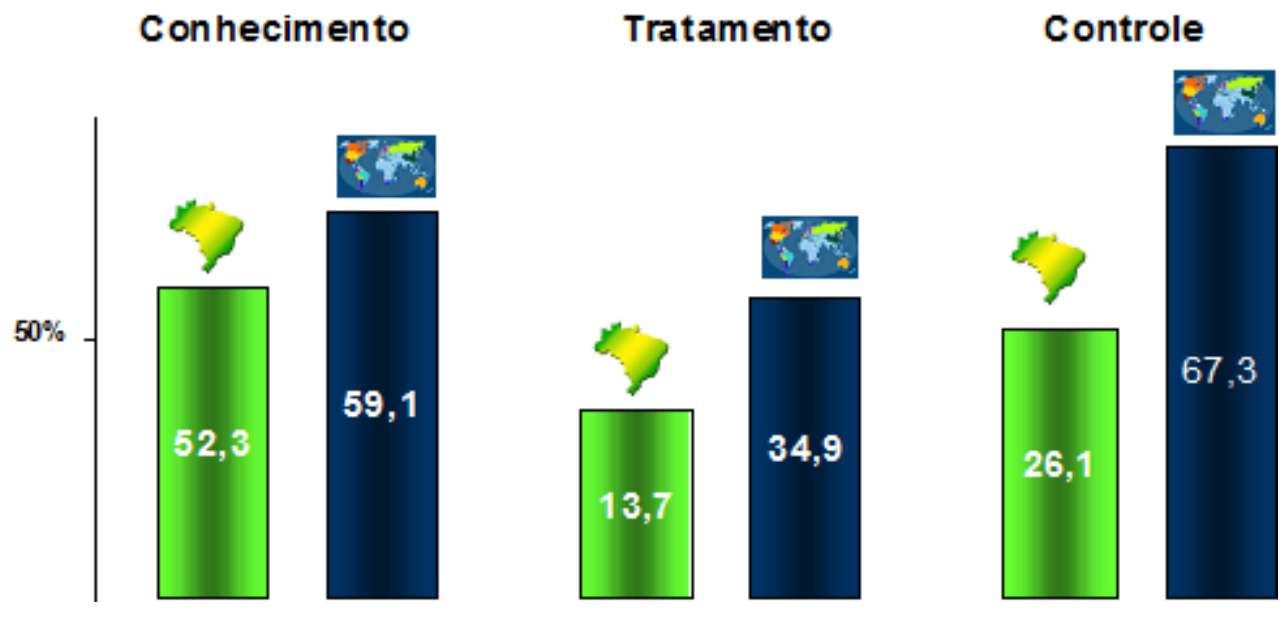

Figura 8. Conhecimento, tratamento e Controle da Hipertensão Arterial no Brasil e no mundo 1.

\begin{abstract}
SUMMARY
Systemic Arterial Hypertension (SAH) is a highly prevalent disease causing high morbidity and mortality if not adequately diagnosed and properly treated.

The diagnosis depends on a correct measurement of arterial blood pressure (ABP), with alternative methods to the conventional office measurement being currently used, such as Ambulatory Blood Pressure Monitoring (ABPM) or Home Blood Pressure Monitoring (HBPM).

An appropriate stratification of the additional risk besides the ABP value is essential for treatment planning and for achieving the desired goals for each group of individuals.

It is necessary and desirable to maintain the patients under treatment in order to obtain the benefits derived from pharmacological or non-pharmacological treatment.
\end{abstract}

Key-Words: Essential Arterial Hypertension. High Blood Pressure Diagnosis. High Blood Pressure Treatment.

\section{Referências Bibliográficas}

1. VI Diretrizes Brasileiras de Hipertensão. Arq Bras Cardiol. 2010; Supl. 1: 1-40

2. Giuseppe Mancia (Chairperson) (Italy)_, Robert Fagard (Chairperson) (Belgium)_, Krzysztof Narkiewicz (Section coordinator) (Poland), Josep Redo'n (Section co-ordinator) (Spain), Alberto Zanchetti (Section co-ordinator) (Italy), Michael Bo" hm (Germany), Thierry Christiaens (Belgium), Renata Cifkova (Czech Republic), Guy De Backer (Belgium), Anna Dominiczak (UK), Maurizio Galderisi (Italy), Diederick E. Grobbee (Netherlands), Tiny Jaarsma (Sweden), Paulus
Kirchhof (Germany/UK), Sverre E. Kjeldsen (Norway), Ste'phane Laurent (France), Athanasios J. Manolis (Greece), Peter M. Nilsson (Sweden), Luis Miguel Ruilope (Spain), Roland E. Schmieder (Germany), Per Anton Sirnes (Norway), Peter Sleight (UK), Margus Viigimaa (Estonia), Bernard Waeber (Switzerland), and Faiez Zannad (France). . 2013 ESH/ESC Guidelines for themanagement of arterial hypertension TheTask Force for the management ofarterial hypertension of the European Society ofHypertension (ESH) and of the European Society of Cardiology (ESC). J Hypertens. 2013, 31:1281-357

3. Oparil S, Weber M. Hypertension 2007, 1st. Edition. 
4. Guideline ESH/ESC 2003. J Hypertens. 2003; 21:1779-86.

5. Cesarino CB, Cipullo JP, Martin JFV, Ciorlia LA, Godoy MRP, Cordeiro JA, Rodrigues IC. Prevalencia e fatores sociodemograficos em hipertensos de Sao Jose do Rio Preto. Arq Bras Card. 2008; 91:31-5.

6. Rosario TM, Scala LCNS, Franca GVA, Pereira MRG, Jardim PCBV. Prevalencia, controle e tratamento da hipertensao arterial sistemica em Nobres, MT. Arq Bras Card. 2009; 93: 672-8.

7. Pereira M, Lunet N, Azevedo A, Barros H. Differences in prevalence, awareness, treatment and control of hypertension between developing and developed countries. J Hypertension. 2009; 27: 963-75.

8. Salmond CE, Prior IA, Wessen AF Blood pressure patterns and migration: a 14-year cohort study of adult Tokelauans. Am J Epidemiol. 1989;130:37-52

9. Graudal NA, Hubeck-Graudal T, Jurgens G. Effects of lowsodium diet vs. high-sodium diet on blood pressure, renin, aldosterone, catecholamines, cholesterol and triglyceride (Cochrane Review). Am J Hypertens. 2012; 25:1-15.

10. Reis DJ The brain and hypertension: reflections on 35 years of inquiry into the neurobiology of the circulation. Circulation. 1984;70(5 Pt 2):III31-45.

11. Kannel WB, Brand N, Skinner JJ Jr, Dawber TR, McNamara PM. The relation of adiposity to blood pressure and development of hypertension. The Framingham study. Ann Intern Med. 1967; 67:48-59.

12. Sega R, Trocino G, Lanzarotti A, Carugo S, Cesana G, Schiavina $\mathrm{R}$, et al. Alterations of cardiac structure in patients with isolated office, ambulatory, or home hypertension data from the general population (Pressione Arteriose Monitorate E Loro Associazioni [PAMELA] Study). Circulation. 2001;104;138592.

13. Hansen TW, Jeppesen J, Rasmussen S, Ibsen H, Torp-Pedersen C. Ambulatory blood pressure monitoring and risk of cardiovascular disease: a population based study. Am J Hypertens. 2006;19:243-50

14. Moore LL, Visioni AJ, Qureshi MM, Bradlee ML, Ellison RC, D'Agostino R. Weight loss in overweight adults and the longterm risk of hypertension: the Framingham study. Arch Intern Med. 2005;165: 1298-303.

15. Halperin RO, Sesso HD, Ma J, et al. Dyslipidemia and the risk of incident hypertension in men. Hypertension 2006, 47:45-50.

16. Haffner SM, Miettinen H, Gaskill SP, Stern MP. Metabolic precursors of hypertension. The San Antonio Heart Study. Arch Intern Med 1996, 156: 1994-2001.

17. Zhang Y, Lee ET, Devereux RB, Yeh J, Best LG, Fabsitz RR, et al. Prehypertension, diabetes, and cardiovascular disease risk in a population based sample: the Strong Heart Study. Hypertension 2006; 47:410-14.

18. The ACCORD Study Group. Effects of intensive blood-pressure control in type 2 Diabetes mellitus. N Engl J Med 2010. DOI:10.1056/NEJMoa1001286.

19. Pepine CJ, Handberg EM, Cooper-DeHoff RM, Marcos RG , Kowey $\mathrm{P}$, Messerli $\mathrm{FH}$, et al. A calcium antagonist vs. a noncalcium antagonist hypertension treatment strategy for patients with coronary artery disease. The International
Verapamil-Trandolapril Study (INVEST): a randomized controlled trial. JAMA. 2003; 290: 2805-16.

20. Stevens VJ, Obarzanek E, Cook NR, Lee IM, Appel LJ, Smith West $\mathrm{D}$, et al. Longterm weight loss and changes in blood pressure: results of the trials of hypertension prevention, phase II. Ann Intern Med 2001; 134:1-11.

21. Xin X, He J, Frontini G, Ogden LG, Motsamai OI, Whelton PK. Effects of alcohol reduction on blood pressure. A metaanalysis of randomized controlled trials. Hypertension. 2001;38:1112-17.

22. Rossi A, Dikareva A, Bacon S, Daskalopoulou S. The impact of physical activity on mortality in patients with high blood pressure: a systematic review J Hypertens. 2012; 30:1277-88.

23. Sacks FM, Svetkey LP, Vollner WM. Effects on blood pressure of reduced dietary sodium and the Dietary Approaches to Stop Hypertension (DASH) Diet N Engl J Med. 2001; 344:3-10.

24. National Institute of Health State-of-The Science Conference Statement: Tobacco use: Prevention, Cessation, and Control. NIH Conference. Ann Intern Med 2006; 145: 839-44.

25. Appel LJ, Moore TJ, Obarzanek E, Vollmer WM, Svetkey LP, Sacks FM, et.al. A clinical trial of the effects of dietary patterns on blood pressure. DASH Collaborative Research Group. N Engl J Med. 1997; 336:1117-24.

26. Third Report of the National Cholesterol Education Program (NCEP) Expert Panel on Detection, Evaluation, and Treatment of High Blood Cholesterol in Adults (Adult Treatment on Panel III) Final Report. Circulation. 2002;106:3143

27. Aburto N.J, Hanson S, Gutierrez H. Effect of increased potassium intake on cardiovascular risk factors and disease: systematic review and meta-analyses BMJ 2013;346:1-78

28. Torres MR, Sanjuliani AF. Does calcium intake affect cardiovascular risk factors and/or events? Clinics (Sao Paulo). 2012 Jul;67:839-44.

29. Houston MC, Harper KJ. Potassium, magnesium, and calcium: their role in both the cause and treatment of hypertension. $\mathrm{J}$ Clin Hypertens (Greenwich). 2008 Jul;10(7 Suppl 2):3-11

30. The Seventh Report of the Joint National Committee on Prevention, Detection, Evaluation, and Treatment of High Blood Pressure: the JNC 7 report. JAMA. 2003 May 21;289:2560-72

31. The ALLHAT Officers and Coordinators for the ALLHAT Collaborative Research Group. Major outcome in high-risk hypertensive patients to angiotensin-converting enzyme inhibitor or calcium channel blocker vs. diuretic. The Antihypertensive and Lipid-Lowering Treatment to Prevent Heart Attack Trial (ALLHAT). JAMA 2002; 228: 2981-97

32. UK Prospective Diabetes Study Group. Efficacy of atenolol and captopril in reducing risk of macrovascular and microvascular complications in type 2 diabetes. UKPDS 39. BMJ 1998; 317: 713-20.

33. The Heart Outcomes Prevention Evaluation Study Investigators. Effects of an angiotensin converting enzyme inhibitor, ramipril, on cardiovascular events in high-risk patients.N Engl J Med 2000; 342: 145-53.

34. Dahlöf B, Devereux RB, Kjeldsen SE, Julius S, Beevers G, de Faire $U$, et al. Cardiovascular morbidity and mortality in the losartan intervention or endpoint reduction in hypertension study (LIFE): a randomized trial against atenolol. Lancet 2002; 359: 995-1003. 
35. Stassen JA, Fagard R, Thijs L. Randomized double-blind comparison of placebo and active treatment for older patients with isolated systolic hypertension. The Systolic hypertension in Europe (SYST-EUR). Lancet 1997; 350: 757-64.

36. McMurray JJ, Pitt B, R Latini, Maggioni AP, Salomão SD, Keefe $\mathrm{DL}$, et al. Effect of the oral direct renin inhibitor aliskiren in patients with symptomatic heart failure. Circ Heart Fail 2008;1:17-24.

37. Mason RP, Giles TD, Sowers JR. Evolving mechanisms of action of beta blockers: focus on nebivolol. J Cardiovasc Pharmacol. 2009;54:123-8.
38. Parving HH, Brenner BM, McMurray JJV, de Zeeuw D, Haffner SM, Solomon SD, et.al. Cardiorenal End Points in a Trial of Aliskiren for Type 2 Diabetes. N Engl J Med. 2012; 367:220413.

39. Parving H, Persson F, Lewis JB, Lewis EJ, Hollenberg NK. Aliskiren combined with losartan in type 2 diabetes and nephropathy. N Engl J Med 2008;358:2433-46.

40. Pereira, Ana Augusta Maria, Aspectos psicológicos envolvidos na não adesão. In Nobre F, Mion Júnior D. Adesão ao tratamento: $O$ grande desafio das doenças crônicas e da Hipertensão Arterial. Editora Casa Leitura Médica, 2013. Páginas 35-43. 